\title{
PHYSICAL ACTIVITY AND THE DIET IN POPULATIONS DIFFERING IN SERUM CHOLESTEROL ${ }^{1}$
}

\author{
BY ANCEL KEYS, JOSEPH T. ANDERSON, MARIO ARESU, ${ }^{2}$ GUNNAR BIORCK, \\ JOHN F. BROCK, ${ }^{4}$ B. BRONTE-STEWART, FLAMINIO FIDANZA, ${ }^{5}$ \\ MARGARET HANEY KEYS, HAQVIN MALMROS, ${ }^{3}$ ARRIGO \\ POPPI, ${ }^{6}$ TEODORO POSTELI, ${ }^{6}$ BENGT SWAHN, ${ }^{3}$ AND
}

ALFONSO DEL VECCHIO?

(From the Laboratory of Physiological Hygiene, University of Minnesota, Minneapolis, Minn.)

(Submitted for publication February 13, 1956; accepted July 5, 1956)

Previously we have reported that samples of men from various populations differ in the average concentration of cholesterol in the blood serum so that, in general, the cholesterol level tends to be directly related to the proportion of the total calories provided by fats in the habitual diet of the population (1-6). Differences in the cholesterol content of these diets cannot account for the differences in the serum (7).

These observations are confirmed by other recent studies (8), but the question has been asked as to whether differences in habitual physical activity could not account for the findings. The suggestion has been made that "a large muscle mass or a large energy expenditure is the effective agent and that this, not the diet, is the important element in preventing hyperlipemia" $(8$, p. 1010).

In some areas it is easy to show that the more prosperous men, who are usually less active physically than the rest of the local population, tend to have higher cholesterol values than men representing the rest of the community. We found this to

1 The collection and analysis of the data cited here was made possible by grants of funds and other assistance from the American Heart Association, New York, the Minnesota Heart Association, St. Paul, the National Dairy Council, Chicago, The American Dairy Association, Chicago, the Schweppe Foundation, Chicago, the South African Council on Scientific and Industrial Research, Johannesburg, Mr. David Winton and Associates, Minneapolis, and interested organizations at Lund and at Malmö, Sweden.

2 Clinica Medica, University of Cagliari, Sardinia, Italy.

8 Departments of Medicine, University of Lund, Lund and Malmö, Sweden.

4 Department of Medicine, University of Cape Town, Union of South Africa.

Institute of Physiology, University of Naples, Italy.

- Clinica Medica, University of Bologna, Italy.

7 Department of Pharmacology, University of Milan, Italy. be true in Madrid, Spain (4), in Naples, Italy (9), and in Cape Town, South Africa (6). Superficial consideration of these data might suggest that the observed cholesterol differences are causally related to physical activity since men in the more prosperous groups often tend to be relatively inactive physically.

It is now well established experimentally that changes in the proportion of calories provided by fats in the diet, without change in total calories or in physical activity, produce changes in the serum cholesterol concentrations in man (10-17) rats (18) and rabbits (19). Such evidence does not exclude the possibility that physical activity may also have an effect on the serum cholesterol level and, in fact, a slight effect is indicated in acute experiments on man $(20,21)$.

But the relative unimportance of differences in physical activity was indicated from studies in Naples, Italy, and in Malmö, Sweden. In Naples and Malmö, clerical workers, members of the city fire departments and heavy manual workers were studied in parallel from which it appeared that the dietary and not the physical activity characteristic of the group is the major factor in regard to serum cholesterol $(5,22)$. Much new evidence from Bologna, Italy, Sardinia, Minnesota and South Africa, is now at hand to allow a more precise examination of the question. The present paper summarizes these data and comparisons in regard to the factor of physical activity.

\section{METHODS AND MATERIALS}

In all cases the population samples comprised men presumed to be reasonably representative of their class in the community who were gainfully employed at their regular and habitual occupation and who were judged to be clinically healthy on the basis of a brief interview, a 
physical examination and, in most of these series, a 9to 12-lead electrocardiogram.

In the present study there was no effort to obtain stratified samples of men representing all modes of life, income and other characteristics in their community. The purpose was to study samples of men conforming to broad categories of occupational physical activity, who would be comparable in age and clinical "health," whose diets could be at least roughly specified in regard to fat content, and whose general manner of life, including their diets, did not depart grossly from that of the other men of similar category in their own community.

In each case arrangements for the study were first made with the employers, labor union officials and influential leaders in the job category so that the major selection had to do with the organization and not with the individuals. No organizations with unorthodox methods of employment or selection of men were involved. Uninvited "volunteers" were discouraged from seeking appointments as were men of unusual habits, diet or health notions or past history. Pressures of various kinds were employed to assure that the men actually studied represented a large and unbiased fraction of all of the men in each job category and age group in the various organizations selected for study.

The actual physical activity on the job, some personal habits such as smoking and the use of alcohol, and adherence to or departure from the general local dietary pattern were ascertained by interviewing each man at the time of examination. Men found to show signs or histories of clinical disorder or whose diets were discovered to be atypical of the local group were discarded; fortunately these cases were rare. A few men whose physical activity did not conform to the expectation on the basis of job title were re-classified.

Except in rare instances, blood samples were drawn in the morning after a short rest in the supine position and before taking the first heavy meal of the day. The relative unimportance of achieving strictly basal conditions for serum cholesterol studies has been reported elsewhere (20).

Serum total cholesterol was measured, usually in duplicate, by a slight modification (23) of the method of Abell, Levy, Brodie, and Kendall (24). Identical cholesterol standards, prepared and checked in Minneapolis, were used for all of the series. The cholesterol in the alpha and beta lipoproteins was measured in several of the series by an adaptation of the total cholesterol method to the fractions separated by paper electrophoresis (23).

In all of the series identity of procedure and analysis was guaranteed by the fact that at least some of the same technical personnel participated in the work in all of the series of studies except those in Malmö and there Dr. Bengt Swahn, who was in charge of the chemical analyses, had just previously worked with the laboratory team in the work in Naples. As a final check on assuring strict comparability of the cholesterol results, a large number of samples were analyzed in duplicate both in Minneapolis and in one of the other field centersNaples, Cape Town, Bologna. The highly satisfactory agreement in these independent checks in different laboratories has been reported elsewhere (23).

\section{Dietary estimates}

The populations considered here were selected for study mainly because their habitual diets cover a wide range of relative fat content with relatively sharp and consistent differences between them as indicated by personal knowledge of the several cultures and by data on food balances of the regions. In most of the studies each man was queried about his personal diet, particularly in regard to the consumption of fats and fatty foods, but these individual data are considered to be adequate only for estimating the relative intakes of fats and to show that the men studied did, in fact, conform to the general dietary pattern of the region.

The values given in Table $I$ are derived from a variety of sources, as indicated below. Their precision is obviously limited but there is no doubt that, at least, they correctly give the order of fatness of the diets: Minnesota $>$ Malmö $>$ Bologna $>$ Sardinia $>$ Naples $>$ Cape Province Bantu. Further, it is certain that the diet of the Cape Province Europeans is in the same general range of fat proportion as that of the Minnesotans and that the Cape Coloured men eat a diet more like, in regard to fat, that of the men of Sardinia or Bologna.

The Minnesota value in Table I is derived: a) from household surveys in Minneapolis and St. Paul covering 253 families in the winter and 166 families in the spring of 1948 , indicating respectively, 41.1 and 43.9 per cent of calories from fats (25) and, b) one-week individual records of total food consumption of 119 middle-aged men, some of whom limited their diet to control weight, in the same cities in 1953 and 1954 . The average for this careful survey (7) was 42 per cent of calories from fats but when full allowance was made for fat-trimming at the table and grease adhering to the plates (plate waste) the average was 39.5 per cent fat calories in the food actually eaten. It should be noted that for comparison with the other populations considered, the former figure, i.e., the 42 per cent uncorrected for plate waste, would be more appropriate because allowances for such plate waste are not available for the other populations.

The general order of relationship between the diet of the U. S., Sweden and Italy is indicated in such broad summaries as those of the U. S. Department of Agriculture (26) and the F.A.O. Second World Survey (27) but more useful details are given in the F.A.O. food balance sheets (28) and in the agricultural statistics, supplied by the respective Departments or Ministries of Agriculture, of the countries concerned. These indicate averages for recent years for the U. S., Sweden and Italy, respectively, or $41,37.5$ and 20 per cent of calories from fats.

For Malmö, and the Province of Skane generally, the true figure may be a trifle higher than the estimated average for all of Sweden. Such a difference is locally thought to exist and a recent survey in Skåne (29) tends to bear this out. Further, this survey shows that the 
habitual diets of the different social classes in this part of Sweden are remarkably similar, though, as will be noted later, there may be a tendency for heavy workers to derive a somewhat smaller percentage of their calories from fats than does the rest of the population.

For Bologna, the value listed was obtained by calculation from data provided by Professor Arrigo Poppi and from detailed lower and middle-class dietaries compiled by Dr. Iasonni which agreed, in general, with the local data on food disappearing at the retail level (30). In Italy it is possible to reconstruct a major part of the diet for any town because most foods, including those locally produced by individual farmers, are subject to tax ("imposte di consume") which is enforced at all points of entry to the town. The food "disappearance" data contained in the voluminous statistical reports of the Comunes of Bologna and Naples $(30,31)$ bear out the difference between the two regions. It is well known in Italy that the diet of Bologna, and of nearby Modena, is much higher in fats than the national Italian average and the region is traditionally known as "Emilia la grasse" (Emilia the land of fats). This is abundantly clear to anyone who alternately lives in Bologna and other Italian cities such as Naples and Cagliari. Besides the much greater use of fat-rich sauces ("Bolognese"), most of the bread is made with about 5 per cent of its dry weight as fat (usually half olive oil and half lard), which is never done in Naples or Sardinia, and the local "pasta" (spaghetti, etc.) also differs in that it is often made with eggs and fats. Finally, the food habits recorded by the men actually used as subjects showed that their fat consumption averaged much more than that of the typical Neapolitans studied-more frequent use of butter, fat meat, whole milk cheese, "caffe latte" (hot milk with coffee extract), and more liberal use of olive oil, as well as the habitual use of bread containing fat. Nevertheless, the true average for the subjects studied in Bologna cannot be specified more accurately than being between 27 to 33 per cent of calories from fats.

For Sardinia, many data are summarized by Brotzu (32). The most recent values show a range from 13.6 per cent fat calories for poor laborers to 31.6 for families in reasonably comfortable circumstances in one study and, in another study, averages of 20.9 and 23.9 per cent were obtained for two rural areas in the spring and summer of 1952. These data suggest an average value of around 25 per cent for the urban population and somewhat less for Bacu Abis. In our own surveys on the individuals reported here we concluded that the diets in Cagliari and

\section{TABLE I}

Percentage of total dietary calories supplied by fats in the average diets of the populations studied

Minneapolis, Minnesota

Malmö, Sweden

Cape Town, Europeans

Bologna, Italy

Cape Town, Coloured

Sardinia (Cagliari, Bacu Abis)

Naples, Italy

Cape Town, Bantu
38
$35-40$
Bacu Abis, though they resemble the Neapolitan pattern, were richer in fats at the time (Spring, 1955) of our survey. This was indicated, in particular, by the more frequent use of meat, fish and eggs.

For Naples, averages of 18 to 21 per cent fat calories were obtained in two surveys of local mental hospitals $(33,34)$ by computation from the diets of the Fire Department, and by one-week food consumption records in 1954 of a few of the families of our subject group who were believed to represent the general working class. Further, total food "disappearance" data indicate that Naples corresponds closely to the value of 20 per cent fat calories estimated for all of Italy from food balances. Finally, the results from individual dietary interviews with the Neapolitan subjects conformed to the same pattern repeatedly found for the general population of this area by Professor Gino Bergami-about 70 per cent of calories from cereal products (plain bread and pasta), small portions of meat or fish not oftener than 2 or 3 times a week, fairly liberal amounts of sugar and of fresh cheese made from skimmed milk, fruit and green vegetables several times daily, whole milk only in breakfast coffee, no butter or margarine, much tomato paste, 100 to $200 \mathrm{ml}$. of olive oil a week, and very small amounts of whole milk cheese ("Parmesan").

The values for Cape Town in Table $I$ are from the household surveys of Batson (35) whose value of 35 per cent fat calories for the local European does not pertain to the upper economic class. It was estimated that the value for the upper economic class of Europeans, who constituted a considerable proportion of the European men studied by us, there, is nearer 40 per cent.

Each subject studied at Cape Town was given a detailed dietary interview by a trained local social worker who was assisted by a dependable Bantu in the interviews with members of that race. This provided reasonably satisfactory figures for the fats and fatty foods but the absolute total calorie consumption from all sources could not be reliably estimated in this way. Accordingly, for some purposes (as in Table V) we believed it more conservative to compare the men in Cape Town in terms of relative fat consumption. The general dietary patterns found in our interviews corresponded well with those recorded by Professor Batson (35) in his studies on sample families in these same populations.

\section{Physical activity}

For the present purpose the men may be classified according to physical activity into broad groups:

1) Light work. This category includes sedentary workers and men whose jobs make very little demand on muscular effort-clerks, shopkeepers, inside watchmen, traders, draftsmen, etc. Parenthetically, it was observed that almost no men in any population, in South Africa as elsewhere in our experience, were willing to consider themselves-or to accept the label without much qualification-as being sedentary.

2) Moderate work. This category includes men whose jobs infrequently entail physically violent or severe muscular effort but who are fairly active during a good part 
TABLE II

Firemen (lines 1,2, 5), policemen (line 3), firemen and policemen (line 4), studied in 1954 and 1955. Ages 40 to 51 inclusive

\begin{tabular}{lccccc}
\hline \hline & & & \multicolumn{2}{c}{ Total cholesterol } \\
\cline { 5 - 6 } \multicolumn{1}{c}{ Place } & $\mathrm{N}$ & $\begin{array}{c}\text { Mean } \\
\text { age }\end{array}$ & & Mean & S.E. \\
\hline 1. Minneapolis & 119 & 44.2 & 250.2 & \pm 3.8 \\
2. Malmö & 38 & 44.9 & 237.2 & \pm 7.0 \\
3. Bologna & 28 & 45.1 & 193.8 & \pm 7.1 \\
4. Cagliari & 29 & 45.2 & 193.8 & \pm 6.6 \\
5. Naples & 76 & 43.8 & 169.5 & \pm 4.0 \\
& & & & & \\
\hline
\end{tabular}

of the work day-machine operators, carpenters, painters, light warehouse workmen, janitors, outside watchmen, streetcar servicemen, mechanics, etc. Firemen and policemen might be assignable to this "moderate activity" classification but it is useful to consider them separately; they represent a relatively special and homogeneous segment of that class whose activity is light, on the average, but occasionally may be very strenuous. The Minneapolis firemen may be somewhat less physically active than their counterparts in the European cities who tend to have a more regular program of calisthenics and drill. Most of the policemen in these European cities were on patrol duty on foot; only a few of those studied were "desk-bound" or "motorized."

3) Heavy work. This category includes men whose jobs regularly involve much heavy lifting and severe muscular effort in steel mills, shipyards, foundries, coal mines, manually handling heavy boxes and barrels in warehouses, loading ship cargoes, road building, quarrymen, etc.

\section{RESULTS}

Tables II, III, and IV summarize the data for serum total cholesterol in 290 firemen and policemen, 182 men engaged in light work, and 247 men regularly employed in heavy manual labor. For each of the physical activity categories the age of the men is standardized. The data clearly show that the differences between the serum cholesterol averages of the population samples are relatively

TABLE III

Light workers, ages 40 to 59, inclusive

\begin{tabular}{lccccc}
\hline \hline & & & \multicolumn{2}{c}{ Total cholesterol } \\
\cline { 5 - 6 } \multicolumn{1}{c}{ Place } & N & $\begin{array}{c}\text { Mean } \\
\text { age }\end{array}$ & & Mean & S.E. \\
\hline Cape Town & & & & \\
$\quad$ European & 64 & 48.8 & 243.8 & \pm 5.9 \\
Malmö & 46 & 49.3 & 239.4 & \pm 6.2 \\
Bologna & 17 & 47.1 & 219.9 & \pm 15.6 \\
Naples* & 22 & 48.2 & 164.5 & \pm 7.1 \\
Cape Town & 33 & 48.0 & 177.0 & \pm 6.0 \\
$\quad$ Bantu & 33 & & &
\end{tabular}

* Clerical employees of the city of Naples.
TABLE IV

Heavy manual workers, ages 40-59

\begin{tabular}{lccccc}
\hline \hline & & Mean & \multicolumn{2}{c}{ Total cholesterol } \\
\cline { 5 - 6 } \multicolumn{1}{c}{ Place } & N & age & & Mean & S.E. \\
\hline Malmö & 88 & 49.2 & 219.1 & \pm 3.7 \\
Bacu Abis & 59 & 44.9 & 181.3 & \pm 4.3 \\
Naples & 71 & 49.2 & 160.2 & \pm 3.6 \\
Bantu & 29 & 46.4 & 147.6 & \pm 3.8
\end{tabular}

independent of the habitual physical activity but, in each activity group, the correspondence of the serum values with the dietary habit is pronounced. For men of the same age and engaged in work of the same general level of physical effort, the group average differences between those on highest fat diets and those on the lowest fat diets are $80.7 \mathrm{mg}$. per cent for firemen and policemen, 66.7 for light workers and 71.5 for heavy workers and these differences, as well as many other differences within the tables, are highly significant statistically.

The comparisons summarized in Figure 1 are particularly informative because they cover 3 ac-

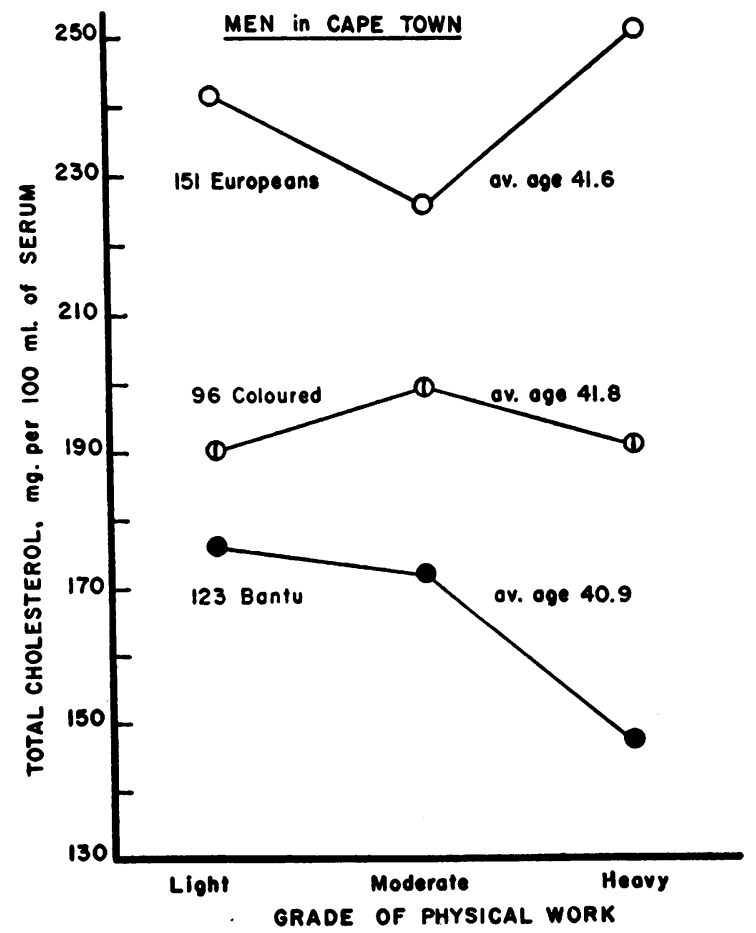

Fig. 1. Mean Values for Serum Total Cholesterol Concentration, in Mg. PER 100 ML., for MEN in CAPE Town, Aged 30 to 51, Classified According to the Physical Activity Demanded in Their Habitual Work 
tivity levels, graded on the same system, for each of 3 dietary-pattern groups in the same area. It should be observed that the 370 men summarized here are age-matched and were resident in a single urban area with a mild temperate climate where there are no complications of tropical disease or of differential exposure to bitter cold or to extremes of heat. Obviously the differences between the cholesterol values of the Europeans, the Cape Coloured men and the Bantu are not dependent on differences in physical activity and, within the first two of these groups, there is no indication of an effect of the degree of physical activity.

Among the Bantu, however, the men doing heavy manual labor have significantly lower cholesterol values than the other Bantu and the question may be asked as to what this implies. This question becomes more intriguing when it is noted that a similar, though smaller, trend was found in some other populations. For example, heavy manual workers aged 40 to 59 in Malmö averaged $20.1 \mathrm{mg}$. per cent lower in serum cholesterol concentration than the light workers of the same age in the same place, the difference being statistically significant. On the Island of Sardinia, too, the coal miners of Bacu Abis tended to have lower cholesterol values than their countrymen engaged in moderate or light work in Cagliari.

It is conceivable that this tendency for heavy manual workers to have low cholesterol values is, in fact, related primarily to their high level of physical activity, but a persuasive dietary explanation can also be offered which explains not only the difference between the activity classes of the Bantu but also the lack of differences between the activity classes within the Cape Coloured and the European populations.

Table $\mathrm{V}$ summarizes the data on the relative dietary fat consumption for men aged 30 to 59 years in the three populations in Cape Town, classified according to their habitual level of physical work. For each category, Table $\mathrm{V}$ gives the mean and its standard error for fat intake expressed as a percentage of the average for the entire series of 468 men. Among the Bantu, the heaviest workers have much lower fat intakes than the other Bantu, but this difference is not evident among the Coloured and European populations.

It should be noted, further, that the data in Table $\mathrm{V}$ refer to absolute amounts of fat con-
TABLE V

Relative average fat intake, as percentage of the mean intake of all men, in three activity classes of each of three ethnic groups, in Cape Town

\begin{tabular}{llcrc}
\hline \hline & & & \multicolumn{2}{c}{ Relative fat intake } \\
\cline { 4 - 6 } Group & Work & $\begin{array}{c}\text { No. } \\
\text { men }\end{array}$ & Mean & S.E. \\
\hline Bantu & Light & 52 & 75.2 & \pm 6.8 \\
Bantu & Medium & 97 & 74.1 & \pm 5.8 \\
Bantu & Heavy & 40 & 51.2 & \pm 6.8 \\
& & & & \\
Coloured & Light & 32 & 104.8 & \pm 4.9 \\
Coloured & Medium & 77 & 115.6 & \pm 4.5 \\
Coloured & Heavy & 16 & 109.3 & \pm 10.9 \\
& & & & \\
European & Light & 78 & 122.3 & \pm 2.9 \\
European & Medium & 57 & 129.3 & \pm 6.6 \\
European & Heavy & 19 & 143.7 & \pm 12.9 \\
& & & &
\end{tabular}

sumed, with no allowance for the fact that the total calorie consumption is related to the degree of physical activity. But if, as we suspect, the proportion of dietary calories provided by fats is more important in regard to the serum cholesterol level, then it is clear that the inverse relationship between dietary fat and physical activity of the Bantu is even more marked than indicated in Table V. And for the Coloured and European groups it appears that there may be some tendency for the proportion of fat in the diet to decrease with increasing physical activity and the corresponding increase in total calories. For example, if we take the reasonable figures of $2,500,3,000$ and 3,500 calories per day to represent the average total energy consumption for calorie balance, respectively, in the light, moderate and heavy work categories, it appears that the proportion of calories from fats is about 20 per cent higher in the diet of the Europeans in light work than in the diet of their fellows in heavy work. But the corresponding figure of the Bantu in light work is more than 100 per cent higher than that for the Bantu in heavy work.

\section{Total versus beta lipoprotein cholesterol}

In this paper attention is concentrated on the total serum cholesterol. However, it should be noted that the differences between these population groups are equally striking when comparison is made in terms of the cholesterol contained in the beta lipoprotein fraction. In general, the percentage of the cholesterol found in the beta lipoprotein fraction rises with increasing total 
cholesterol in these series. For example, the mean percentages of the total cholesterol found in the beta lipoprotein fraction in the serum of men aged 40 to 49 , inclusive, in Cape Town are 71.87 per cent for 83 Bantu. 75.45 per cent for 60 Coloured, and 83.28 per cent for 77 European men. In other words, the differences between these ethnic groups are greater in terms of beta lipoprotein cholesterol than in terms of total cholesterol.

Superficially these values may seem to indicate a different relationship than that reported from comparisons of young Nigerian natives with men in the U. S. Mann. Nicol, and Stare (8) concluded that there were large and significant differences in total cholesterol concentrations but that "the serum lipoprotein concentrations of the $\mathrm{Ni}$ gerians were only slightly lower than those of the North Americans and these differences were of doubtful significance" (ibid. p. 1010).

However, it must be observed that in the study by Mann, Nicol, and Stare ( 8 ) the beta lipoprotein was estimated by ultracentrifugation and a measurement depending on the refractive index associated with Gofman's fractions " $S_{f} 12-20$ " and " $\mathrm{S}_{\mathrm{f}} 20-100$." This is not, of course, the same as measuring the beta lipoprotein cholesterol as done here. Further, in their study we note that in regard to the $S_{\mathrm{f}} 12-20$ fraction, the mean for North Americans was actualy 32 per cent higher than for the Nigerians and that this is significant at the 5 per cent level. It is difficult to establish high statistical significance with relatively small numbers of subjects by the ultracentrifugal method when, as here, the standard deviation, as a percentage of the mean, is as high as \pm 50 per cent (N. Americans) or \pm 57 per cent (Nigerians).

It may be noted that besides the large differences in the proportion of fat calories in the diets of these populations, the total calorie balance. as shown by relative body weights of the men, varied somewhat, though these differences were relatively small. For example, for ages 30 to 59 years, the mean relative body weights, as percentages of the values for equal age and height given in the standard U. S. Medico-actuarial tables, were $101.5 .96 .9,96.9$, and 94.6 per cent, respectively, for men in Cagliari (74 men), Naples heavy workers (106 men). Malmö heavy workers (129 men), and Cape Coloured (124 men).
TABLE VI

Comparison of serum cholesterol values of men subsisting on different diets but matched for age, relative body weight (on U.S. standards) and physical activity*

\begin{tabular}{lcccc}
\hline \multicolumn{1}{c}{ Place } & $\begin{array}{c}\text { Age } \\
\text { years }\end{array}$ & $\begin{array}{c}\text { Relative } \\
\text { weight }\end{array}$ & \multicolumn{2}{c}{$\begin{array}{c}\text { Cholesterol } \\
(\mathrm{mg} . \%)\end{array}$} \\
\hline Minneapolis & 33.0 & 103.2 & 227.7 & \pm 5.9 \\
Naples & 33.2 & 103.8 & 154.2 & \pm 4.9 \\
Difference & -0.2 & -0.6 & 73.5 & \pm 7.7 \\
Cape Town & 47.4 & 102.1 & 203.5 & \pm 9.2 \\
Cagliari & 47.6 & 102.8 & 151.7 & \pm 6.5 \\
Difference & -0.2 & -0.7 & 51.8 & \pm 11.3 \\
& & & &
\end{tabular}

* Forty-nine Minneapolis firemen are compared, in regard to total cholesterol concentration, with 49 Naples firemen, and 35 moderately active men in Cagliari (Sardinia) are compared, in regard to beta lipoprotein cholesterol, with 35 similarly active white (European) men in Cape Town.

These differences in relative obesity do not account for the serum cholesterol differences observed. Illustrations of the fact that the observed serum cholesterol differences are not dependant on differences in relative obesity or overweight are given in Table VI. Forty-nine Naples firemen were matched in regard both to age and to relative body weight with 49 Minneapolis firemen. The age range was restricted to 29 to 39 years and each Neapolitan fireman was matched within 2 years of age and 3 per cent in relative body weight with a corresponding Minneapolis fireman. It will be observed that these men, all of the same occupation, and averaging within 0.2 year of age and 0.6 per cent of relative body weight. differed by a mean of $73.5 \mathrm{mg}$. of cholesterol per $100 \mathrm{ml}$. of serum, the standard error of the difference being only $\pm 7.73 \mathrm{mg}$. per cent.

Table VI also shows a comparison of moderately active men in Sardinia with age-activityobesity mached white men in Cape Town, the beta lipoprotein cholesterol concentration being the variable of focus in this case. Here, too, it is clear that a major difference between the populations in the cholesterol system is not dependent on a difference in relative obesity.

\section{DISCUSSION}

The possibility that, in some populations at least, a difference in serum cholesterol concentration between heavy workers as contrasted with sedentary or light workers is related to differences 
in the diet, deserves much more investigation. It is surprising to discover that there is extremely little information about voluntary dietary habits in regard to fats of men in different grades of work in the same cultural and socio-economic group. One of the few published sets of data indicated that the percentage of fat calories in the average diet of 10 clerks in Scotland was 35.3 while that for 19 coal miners was 33.5 , a slight but significant difference (36).

Dr. M. J. Babcock of the New Jersey Agricultural Experiment Station in New Brunswick, has very kindly supplied us with data obtained in a dietary survey of employees in pharmaceutical factories in his area. Sixty-six men engaged in sedentary and light work were estimated to have an average intake of 3,105 Calories daily, of which $40.39 \pm 1.08$ per cent were supplied by fats. For 13 men engaged in heavy work in the same factories the average calorie intake estimate was 3,880 Cal. of which $37.04 \pm 1.04$ came from fats. The difference between the two types of workers was $3.35 \pm 1.37$, this latter standard error being computed from the pooled variance. This difference is significant at the 2 per cent level of probability $(t=2.44$; for $\mathrm{P}=0.02, \mathrm{t}=2.39)$.

After our work in Sweden was finished, a special dietary study was made in Skåne and in a town in Central Sweden by Persson and Nystrand (29) that bears on this point. Samples of three social (and economic) classes were studied. In spite of a high degree of general similarity between the diets of these classes, there was evidence of a consistent trend for the proportion of fat in the diet to rise with rising social class. Class III, in which the heavy manual workers belong, obviously tends to have the lowest proportion of fat calories in the diet. The tendency is for the heavier workers to get the extra calories used in their work by adding carbohydrate (potatoes, sugar, bread) to their diet. For example, there were no or only trivial differences between the averages for the 3 social classes in regard to the amounts of butter, margarine, milk, cream, cheese and eggs consumed per standard family, or in the frequency of eating meat and fish. But social group III ate much more bread, potatoes and sugar than Class II (which includes office workers and persons in light activity in factories).

Another item of possible significance is the con- sistent difference reported from many parts of the world between urban and rural people. The latter, of course, may generally be assumed to be considerably more active, physically, than the former. In Japan, as an example of a country where the diet is generally very low in fats, the estimate for 1950 is that the urban population gets only 9.7 per cent of its calories from fats while the rural population gets only 6.4 per cent of the calories in this form, i.e., only two-thirds as much in proportion. And in the United States, an example of a highfat diet country, the estimates (1942) for urban families were 42 per cent of calories from fats and 37 per cent for rural diets (25). The same trend is seen in the surveys on the Island of Sardinia (32).

These data show we believe, that the large differences in serum cholesterol concentrations observed when populations of different dietary habits are compared, are not the result of differences in physical activity. This is not meant to imply, however, that physical activity has no effect on cholesterol metabolism. This question needs, and deserves, special study.

\section{SUMMARY}

1. Data on total serum cholesterol are presented for samples of men, classified by age and physical activity, in Minnesota, Malmö, Sweden, Bologna, Naples, the Island of Sardinia and three ethnic groups in Cape Province, South Africa. Data on the cholesterol in the beta lipoprotein fraction in the serum are presented for some of these groups.

2. Differences in physical activity do not explain the large differences in serum cholesterol found when groups with different dietary habits are compared.

3. Within some populations there is a tendency for men in heavy manual labor to have somewhat lower serum cholesterol values than the other men in the population. Among the Bantu, who show this tendency most prominently, it was found that the men in heavy work consume diets lower in fats than the other Bantu and there is other evidence pointing to a general tendency for the composition of the diet to be related similarly to the habitual level of physical activity.

4. It is concluded that the habitual diet, and especially its fat content, has much more influence 
than the physical activity, per se, on the concentration of total cholesterol and beta lipoprotein cholesterol in the blood serum.

\section{ACKNOWLEDGMENTS}

We are grateful for important help to Professors Gino Bergami and F. di Lorenzo and Dr. Orengo in Naples, to Professor Giulio Sotgiu in Bologna, to Drs. Franco and Zedda in Sardinia, to Miss Aileen Moodie and Dr. A. Antonis in Cape Town and to Mrs. Nedra Foster and the other members of the staff of the Laboratory of Physiological Hygiene in Minneapolis.

\section{REFERENCES}

1. Keys, A., Fidanza, F., Scardi, V., and Bergami, G., The trend of serum-cholesterol levels with age. Lancet, 1952, 2, 209.

2. Keys, A., The cholesterol problem. Voeding, 1952, 13, 539.

3. Keys, A., Atherosclerosis: A problem in newer public health. J. Mt. Sinai Hosp., 1953, 20, 118.

4. Keys, A., Vivanco, F., Rodriguez Miñon, J. L., Keys, M. H., and Castro Mendoza, H., Studies on the diet, body fatness and serum cholesterol in Madrid, Spain. Metabolism, 1954, 3, 195.

5. Keys, A., Anderson, J. T., Fidanza, F., Keys, M. H., and Swahn, B., Effects of diet on blood lipids in man: particularly cholesterol and lipoproteins. Clin. Chemistry, 1955, 1, 34.

6. Bronte-Stewart, B., Keys, A., and Brock, J. F., Serum-cholesterol, diet, and coronary heart-disease. An interracial survey in the Cape Peninsula. Lancet, 1955, 2, 1103.

7. Keys, A., Anderson, J. T., Mickelsen, O., Adelson, S., and Fidanza, F., Diet and serum cholesterol in man: lack of effect of dietary cholesterol. J. Nutrition, 1956, In press.

8. Mann, G. V., Nicol, B. M., and Stare, F. J., The beta-lipoprotein and cholesterol concentrations in sera of Nigerians. Brit. M. J., 1955, 2, 1008-1010.

9. Keys, A., Fidanza, F., Scardi, V., Bergami, G., Keys, M. H., and di Lorenzo, F., Studies on serum cholesterol and other characteristics on clinically healthy men in Naples. Arch. Int. Med., 1954, 93, 328.

10. Barker, N. W., The plasma lipoids in arteriosclerosis obliterans. Ann. Int. Med., 1939, 13, 685.

11. Consolazio, F. C., and Forbes, W. H., The effects of a high-fat diet in a temperate environment. J. Nutrition, 1946, 32, 195.

12. Mellinkoff, S. M., Machella, T. E., and Reinhold, J. G., The effect of a fat-free diet in causing low serum cholesterol. Am. J. M. Sc., 1950, 220, 203.

13. Keys, A., Mickelsen, O., Miller, E. v. O., and Chapman, C. G., The relation in man between cholesterol levels in the diet and in the blood. Science, 1950, 112, 79 .
14. Keys, A., Human atherosclerosis and the diet. Circulation 1952, 5, 115.

15. Wilmot, V. A., and Swank, R. L., The influence of low-fat diet on blood lipid levels in health and in multiple sclerosis. Am. J. M. Sc., 1952, 223, 25.

16. Urbach, F., Hildreth, E. A., and Wackermann, M. T., The therapeutic uses of low-fat, low-cholesterol diets. I. Treatment of essential familial xanthomatosis. Am. J. Clin. Nutr., 1952, 1, 52.

17. Mayer, G. A., Connell, W. F., DeWolfe, M. S., and Beveridge, J. M. R., Diet and plasma cholesterol levels. Am. J. Clin. Nutr., 1954, 2, 316.

18. Swell, L., Flick, D. F., Field, H., Jr., and Treadwell, C. R., 1955. Role of fat and fatty acid in absorption of dietary cholesterol. Am. J. Physiol., 1955, $180,124$.

19. Steiner, A., and Dayton, S., Production of hyperlipemia and early atherosclerosis in rabbits by a high vegetable fat diet. Circulation Research, 1956, $4,62$.

20. Keys, A., Serum cholesterol in men in the basal and in the non-basal state. Science, 1956, 123, 29.

21. Mann, G. V., Teel, K., Hayes, O., McNally, A., and Bruno, D., Exercise in the disposition of dietary calories. Regulation of serum lipoprotein and cholesterol levels in human subjects. New England J. Med., 1955, 253, 349.

22. Malmros, H., Biörck, G., and Swahn, B., Hypertension, atherosclerosis and the diet. Proc. 3rd Internat. Cong. Internal Med., 1954, Stockholm. Acta med. Scandinav., 1956, Suppl. No. 312, p. 71.

23. Anderson, J. T., and Keys, A., Cholesterol in serum and lipoprotein fractions, its measurement and stability. Clin. Chem., 1956, 2, 145.

24. Abell, L. L., Levy, B. B., Brodie, B. B., and Kendall, F. E., A simplified method for the estimation of total cholesterol in serum and demonstration of its specificity. J. Biol. Chem., 1952, 195, 357.

25. U. S. Department of Agriculture Food Consumption Surveys. Data supplied by Drs. Hazel Stiebeling and Esther Phipard.

26. U. S. Department of Agriculture. Agricultural production and food consumption in Western Europe. Agric. Monograph 10, Wash., D. C., 1951.

27. Food and Agriculture Organization of the United Nations. Second World Food Survey. Rome, November, 1952.

28. Food and Agriculture Organization of the United Nations. Calorie, protein and fat consumption levels in selected countries. National average food supplies available for human consumption (Food Balance Sheets). Rome, 19 October, 1955.

29. Persson, R., and Nystrand, B., En Undersökning av Matvanorna i tyå Svenska Städer. Sociologiska Institutionen, Lund (Sweden), July, 1955. See also Biörck, G., Persson, R., and Nystrand, B., Något om kostvanor och deras bakgrund $i$ en svensk befolkning. Socialmed. Tidsk., 1955, 32, 357. 
30. Comune di Bologna. Annuario statistico. Ufficio Municipale di Statistica. Bologna, 1951, 1952, 1953.

31. Comune di Napoli. Annuario statistico. Ufficio di Statistica del Comune di Napoli. Naples, 1950, 1951, 1952.

32. Brotzu, G., 1954. La Sardegna. Congresso internazionale di studio sul problema delle aree arretrate. Milano, Dott. A. Giuffre, Ed.

33. De Francisis, P., and Lampitella, P., Rapporti dietetici nelle collettivita' manicomiali. Boll. Soc. ital. biol. sper., 1953, 29, 260.
34. Keys, A., Fidanza, F., and Keys, M. H., Further studies on serum cholesterol of clinically healthy men in Italy. Voeding, 1955, 16, 492.

35. Batson, E., The ethnic differentiation of fat-calorie ratios in household food purchases in Cape Town. J. Soc. Research, 1953, 4, 113.

36. Garry, R. C., Passmore, R., Warnock, G. M., and Durnin, J. V. G. A., Studies on expenditure of energy and consumption of food by miners and clerks, Fife, Scotland, London, 1952. Med. Res. Council Spec. Rept. Ser., 1955, No. 289. 